\title{
Intertrial interval length and discrimination learning in young chicks
}

\author{
BRUCE A. MATTINGLY and JAMES F. ZOLMAN \\ Physiology and Biophysics, Medical Center, University of Kentucky, Lexington, Kentucky 40506
}

\begin{abstract}
One- and 4-day-old chicks were trained on a successive go/no-go discrimination to determine whether an increase in the length of the intertrial interval (ITI) would improve discrimination performance. For all intervals, the 4-day-old chicks showed a greater separation in response latencies on $\mathrm{S}+$ and $\mathrm{S}-$ trials than did the 1-day-old chicks, and chicks of both ages showed a similar decrease in their differential performance on $\mathrm{S}+$ and $\mathrm{S}-$ trials as the ITI length was increased. These results do not support the assumption that the young animal learns best with long rather than short intervals between trials.
\end{abstract}

It has been suggested that immature animals may require more time for memory consolidation than adults, and, consequently, the immature animal may learn best with long rather than short intervals between trials. Administering electroconvulsive shock or drugs at various intervals after avoidance learning in animals of different ages (Doty, 1966; Doty \& Doty, 1964; Dye, 1964; Thompson, 1957) produces age-dependent effects on retention; these results are the primary basis for speculation that the young animal requires a longer consolidation time between trials than the adult. But, as noted in a recent review (Campbell \& Coulter, 1976), the effect of varying the length of intertrial intervals with different age groups has never been tested with simple stimulus-contingent tasks.

The purpose of the present study was to determine whether an increase in the length of the intertrial interval would affect differentially the successive go/no-go discrimination learning of the developing domestic chick. Since significant physiological and behavioral changes occur in the young chick during the first few days after hatching, 1- and 4-day-old chicks were used for age comparisons (see Freeman \& Vince, 1974, for a review). A simple go/no-go successive discrimination task was used in which $\mathrm{S}+$ and $\mathrm{S}$ - trials were both externally cued and presented in a single-alternating sequence. For different groups of chicks these alternating $\mathrm{S}+$ and $\mathrm{S}-$ trials were presented with a fixed intertrial interval of 5,10 , or $20 \mathrm{sec}$.

\section{METHOD}

\section{Subjects}

Eighty-four Vantress by Arbor Acre chicks were incubated and hatched at $37-38^{\circ} \mathrm{C}$ and $56 \%-60 \%$ relative humidity. Each chick was removed from the dark hatching incubator within

Supported by Grant MH 24260 from the National Institute of Mental Health and by NIMH Predoctoral Fellowship 1 F31MH07306 to B. A. Mattingly. We thank Joyce A. Hall and Christie L. Sahley for their assistance in behavioral testing.
$4 \mathrm{~h}$ after hatching, banded, and reared socially in groups of 10-12. The subjects were housed in white Plexiglas brooder compartments $(56 \times 33 \times 23 \mathrm{~cm})$ in a temperature-controlled room $\left(35^{\circ} \mathrm{C}\right)$. Food and water were available ad lib, and the brooder room was illuminated with fluorescent light from 6 a.m. to 11 p.m.

\section{Apparatus}

Behavioral testing was performed in four boxes designed for keypeck conditioning of young chicks using heat reinforcement (see Zolman, Pursley, Hall, \& Sahley, 1975; Zolman, Sahley, \& Hall, 1976). In each box a response key $4 \mathrm{~cm}$ from the floor was tilted away from the chick at a 135-deg angle from the plane of the hardware cloth floor. Each conditioning box was housed individually in a Forma Scientific incubator (Model 3665) in which the ambient temperature was $10^{\circ} \mathrm{C}\left( \pm 1^{\circ} \mathrm{C}\right)$. Another Forma Scientific incubator with an auxiliary 2,000 -W heater was set at $35^{\circ} \mathrm{C}$, and plastic tubing $(20$ and $10 \mathrm{~cm})$ connected each cold incubator with this heat source. A push-pull fan arrangement in the heat incubator maintained a balanced flow of warm air to each conditioning box. Heat onset in each conditioning box was controlled by two rotary solenoids that, when activated, displaced two 10 -cm-diam circular butterfly valves. One valve instantaneously diverted the warm $35^{\circ} \mathrm{C}$ air up through the conditioning box, whereas the other valve opened to replace in the air flow system the same amount of warm air as that diverted. A 24-V light bulb (GE, 1820) located under each conditioning box was also turned on so that reinforcement consisted of both heat and light onset. A white masking noise of $76 \mathrm{~dB}$ re $20 \mu \mathrm{N} / \mathrm{m}^{2}$ was delivered through a $10-\mathrm{cm}$ speaker on the back wall of each conditioning incubator.

Response keys (sensitive to less than $6 \mathrm{~g}$ of force) were mounted directly on IEE 12 -unit in-line projectors that were used to present on the transparent keys either a white $10-\mathrm{mm}$ diam circle on a red background or a white equilateral triangle (10-mm sides) on a red background. Stimulus-reinforcement contingencies were programmed and controlled by BRS electronic solid state modules, and response latencies in $.1 \mathrm{sec}$ were recorded.

\section{Procedure}

Behavioral testing included autoshaping the young chicks to peck the response key and then discrimination testing. One half of the chicks began training when 1 day old $(22.5 \mathrm{~h}$, $\mathrm{SD}=.35$ ); the remainder began training when 4 days old $(98.6 \mathrm{~h}, \mathrm{SD}=1.48)$. On each test day the chicks were removed from their brooder $1 \mathrm{~h}$ before training and isolated in individual white Plexiglas cylinders $(20 \times 15 \mathrm{~cm})$. The autoshaping procedure consisted of an equal number of presentations, in an 
alternating sequence, of each of the two test stimuli. The autoshaping sequence of events was: (a) keylight onset, (b) 16-sec stimulus duration, (c) keylight offset with 8-sec reinforcement $\left(35^{\circ} \mathrm{C}\right.$ air and light), (d) a fixed intertrial interval (ITI) of 5 , 10 , or $20 \mathrm{sec}$ with house light on, (e) keylight onset, etc. When the chick pecked the key during the 16-sec stimulus duration, reinforcement was delivered immediately. A new trial was begun after the ITI. During autoshaping and throughout the experiment, the chick was given a "free" reinforcement while being placed in the test box. Two autoshaping sessions, the first to a criterion of six responses, or 24 trials, and the second session for 24 trials, preceded discrimination testing (Zolman et al., 1975, 1976).

Three discrimination sessions of 48 trials were given on the first day of training and five sessions of 48 trials were given on the second day of training. For one half of the chicks of each age group the white circle was presented on S+ trials, with the white triangle presented on $\mathrm{S}$ - trials; for the rest of the chicks this cue-reinforcement contingency was reversed. A singlealternation reinforcement schedule was used; consequently, both external and internal cues were correlated differentially with reinforcement. Each discrimination session was started with an $\mathrm{S}-$ trial. The sequence of events on a trial during discrimination testing was the same as that during autoshaping with two modifications: (1) No "free" reinforcements were presented at the termination of the 16-sec stimulus duration. (2) Responses on the alternating $\mathrm{S}$ - trials were not reinforced; rather, the chick was held in the dark chamber for $8 \mathrm{sec}$. When a chick did not respond on a trial, the ITI was initiated and $16 \mathrm{sec}$ was recorded for that trial.

\section{RESULTS AND DISCUSSION}

An analysis of variance with repeated measures was performed on mean response latencies across 24-trial blocks of each reinforcement condition ( $\mathrm{S}+$ and $\mathrm{S}-$ ). The analysis of variance was supplemented, where appropriate, by Newman-Keuls post hoc tests (Winer, 1971). For brevity, only the relevant statistical comparisons are discussed, and these include reinforcement as a main effect and the various interactions involving reinforcement as a factor.

Mean response latencies across the eight discrimination sessions for the three ITI groups of 1- and 4-day-old chicks are presented in Figure 1. The chicks of both age groups had shorter overall response latencies on $\mathrm{S}+$ trials than on $\mathrm{S}-$ trials [reinforcement, $\mathrm{F}(1,66)=$ $34.93, \mathrm{p}<.0001$ ], and this differential responding on $\mathrm{S}+$ and $\mathrm{S}-$ trials increased across the eight sessions [Reinforcement by Session interaction, $F(7,462)=$ $24.81, \mathrm{p}<.0001]$.

Across all interval conditions the 4-day-old chicks showed an overall greater difference between S+ and Strial latencies than did the 1-day-old chicks [Age by Reinforcement interaction, $F(1,66)=11.03, p<.005$ ] That is, the mean response latencies on $\mathrm{S}+$ and $\mathrm{S}-$ trials for the 4-day-old chicks were 4.3 and $7.3 \mathrm{sec}$, respectively, whereas the 1-day-old chicks' response latencies were 8.7 and $9.8 \mathrm{sec}$ on $\mathrm{S}+$ and $\mathrm{S}-$ trials. Furthermore, this latency separation between $\mathrm{S}+$ and $\mathrm{S}-$ trials occurred more quickly for the 4-day-old chicks than for the 1-day-old chicks, as revealed by a significant Age by

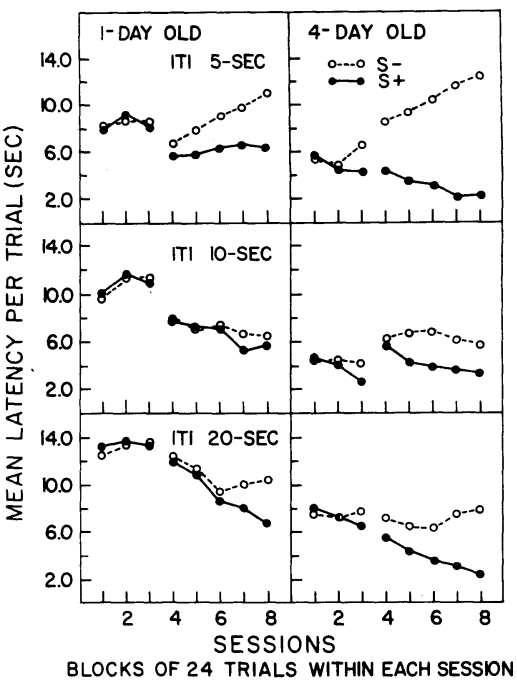

Figure 1. Mean response latencies of 24 trial blocks for 1and 4-day-old chicks tested with a fixed intertrial interval of $5,10,20$ sec.

Reinforcement by Session interaction $[F(7,462)=5.22$, $\mathrm{p}<.001]$.

Both the Interval by Reinforcement and the Interval by Reinforcement by Session interactions were significant $[F(2,66)=7.50, p<.001$ and $F(14,462)=5.78$, $\mathrm{p}<.0001]$. Chicks in the 5 -sec interval condition had a greater latency separation between $\mathrm{S}+$ and $\mathrm{S}-$ trials than did chicks in the 10 - and 20 -sec interval conditions. Chicks in the two longer interval groups did not significantly differ in this latency difference measure. Also, this separation in St and $\mathrm{S}$ - response latencies occurred more quickly in chicks in the 5 -sec interval condition than in the 10- and 20-sec conditions. Since the interactions of Age by Interval by Reinforcement and of Age by Interval by Reinforcement by Session were not significant $[F(2,66)=1.33$ and $F(14,462)=$ $1.67]$, the results indicate that 1- and 4-day-old chicks were affected similarly by the various interval conditions. That is, while there was a significant interval effect, the younger chick's performance did not improve as the length of the ITI was increased. Rather, the 4-day-old chicks showed a greater separation in response latencies on S+ and S- trials than did the 1-dayold chicks across all three intervals, and both age groups showed a similar decrease in their differential performance on S+ and S-trials as the ITI length was increased. These results, therefore, do not support the assumption that the young animal learns best with long rather than short intervals between trials.

\section{REFERENCES}

Campbell, B. A., \& Coulter, X. The ontogenesis of learning and memory. In M. R. Rosenzweig \& E. L. Bennet (Eds.), Neural mechanisms of learning and memory. Cambridge, Mass: MIT Press, 1976. 
Doty, B. A. Age differences in avoidance conditioning as a function of distribution of trials and task difficulty. Journal of Genetic Psychology, 1966, 109, 249-254.

Doty, B. A., \& Doty, L. A. Effects of age and chloropromazine on memory consolidation. Journal of Comparative and Physiological Psychology, 1964, 57, 331-334.

DYE, C. J. Effects of interruption of initial learning upon retention in young, mature, and old rats. Journal of Gerontology, 1964, 24, 12-17.

Freeman, B. M., \& Vince, M. A. Development of the avian embryo. London: Chapman and Hall, 1974.

Thompson, R. W. The effect of ECS on retention in young and adult rats. Journal of Comparative and Physiological Psychology, 1957, 50, 644-646.
WINER, B. J. Statistical principles in experimental design. New York: McGraw-Hill, 1971.

Zolman, J. F., Pursley, D. G., Hall, J. A., \& Sahley, C. L. Form preferences in successive discrimination learning of young chicks. Journal of Comparative and Physiological Psychology, 1975, 89, 1180-1191.

Zolman, J. F., Sahley, C. L., \& Hall, J. A. Ontogeny of conditioned inhibition in domestic chicks. Journal of Comparative and Physiological Psychology, 1976, 90, 1116-1125.

(Received for publication January $31,1979$. ) 